\title{
Improved Shoot-tip Micropropagation of Pistacia Vera L. and the Beneficial Effects of Methyl Jasmonate
}

\author{
Ramon Dolcet-Sanjuan' ${ }^{1}$ and Elisabet Claveria \\ Departament de Genètica Vegetal, Institut de Reçerca i Tecnologia Agroalimentaria, Centre de Cabrils, \\ 08348 Cabrils, Barcelona, Spain
}

Additional index words. pistachio, in vitro, jasmonic acid, JA, MeJA

\begin{abstract}
Micropropagation of Pistacia vera 'Mateur' was improved by adding MeJA to the multiplication and rooting media. Shoot-tip cultures established from grafted trees were maintained on a modified Murashige and Skoog medium containing $5 \mu \mathrm{M}$ BA and $0.05 \mu \mathrm{M}$ IBA. Adding 0.3, 1, or $3.2 \mu \mathrm{M}$ MeJA improved shoot multiplication rates 2.5, 3.0, and 2.3, respectively. There was a significant interaction between the effects of auxin and temperature on the percentage of shoots forming roots. At $25 \mathrm{C}$, the percentage of shoots forming roots was higher in the presence of NAA than IAA or IBA, whereas, at $28 \mathrm{C}$, there was no difference among the auxins. Adding MeJA to the best auxin treatments-31.6 $\mu \mathrm{M}$ NAA at $25 \mathrm{C}$ and $31.6 \mu \mathrm{MAA}$ at $28 \mathrm{C}$-increased the percentage of shoots forming roots and number of roots per shoot but decreased root length. More than $80 \%$ of the shoots rooted at $25 \mathrm{C}$ when $1 \mu \mathrm{M}$ MeJA was added to the root induction medium, which contained 31.6 $\mu$ MAA, and the root elongation medium, without auxin. The large number of short roots induced by MeJA facilitated plantlet transfer to soil and acclimation. Chemical names used: methyl jasmonate (MeJA); $\mathrm{N}^{6}$-benzyladenine (BA), indole-3-butyric acid (IBA), $\alpha$ - naphthaleneacetic acid (NAA), indole3-acetic acid (IAA).
\end{abstract}

Development of pistachio plantations is limited by the absence of adequate nursery stock due to the difficulty of propagating Pistacia plants by conventional methods, such as cuttings or grafting. Consequently, many efforts have centered on establishing in vitro propagation procedures for Pistacia vera and several other Pistacia species (Barghchi and Alderson, 1989).

Systemic bacterial contamination, intense shoot browning due to oxidation of phenolic compounds, shoot-tip necrosis, poor shoot growth, and low multiplication and rooting rates have hampered micropropagation of mature elite Pistacia materials (Barghchi and Alderson, 1989; Martinelli, 1988). Recent improvements include a micrografting technique for $P$. vera (Abousalim and Mantell, 1992), which may help rejuvenation and in vitro establishment of elite mature materials and $\mathrm{CO}_{2}$ enrichment of the atmosphere (Parfitt and Almehdi, 1994), which eliminates the need for sugar and reduces in vitro contamination. Correcting mineral deficiencies in standard media has improved growth (Mederos and Carreño, 199 1; Parfitt and Almehdi, 1994) and overcome leaf and shoot-tip necrosis (Abousalim and Mantell, 1994) in cultured Pistacia shoot tips. However, despite this progress, establishment and multiplication of field-grown mature $P$. vera clones remain problematic. Moreover, while high percentages of shoots forming roots have been obtained with materials derived from seedlings (Barghchi and Alderson, 1983; Parfitt and Almehdi, 1994), rooting shoots obtained from mature clones and plantlet establishment in soil are poor (Martinelli, 1988; Schubert and Martinelli, 1988).

Since the detection of jasmonic acid (JA) in several plant species (Meyer et al., 1984; Yamane et al., 1981), this compound and its fragrant methyl ester (MeJA), collectively referred to as jasmonates, have proved to be important endogenous plant growth

Received for publication 2 Feb. 1995. Accepted for publication 29 June 1995. This work was supported by a grant from the Instituto National de lnvestigaciones Agrarias. Use of trade names does not imply endorsment of the products named nor criticism of similar ones not named. We thank Machteld Mok for suggestions and reviewing the manuscript. The cost of publishing this paper was defrayed in part by the payment of page charges. Under postal regulations, this paper therefore must be hereby marked advertisement solely to indicate this fact.

'To whom reprint requests should be addressed. regulators (Sembdner and Parthier, 1993; Staswick, 1992). They are present in generative and vegetative organs, and exert various physiological activities when applied exogenously. JA was identified as a senescence-promoting substance, enhancing petiole abscission and leaf senescence (Meyer et al., 1984; Parthier, 1990). JA also inhibits seed germination, callus growth, and root elongation (Ravnikar et al., 1990; Yamane et al., 1981), but stimulates root formation (Benedicic et al., 1991; Ravnikar et al., 1990, 1992). That some of JA's effects on different materials seem contradictory may be due to the differences in developmental stages of the plants examined and the difference in concentrations used (Yamane et al., 1981).

We report here 1) establishment and subsequent in vitro growth of a mature elite $P$. vera cultivar rejuvenated by grafting onto seedlings; 2) stimulation and inhibition by different concentrations of MeJA on in vitro shoot multiplication, rooting, and acclimation; and 3) the effects of different auxins and temperatures on in vitro rooting of $P$. vera 'Mateur' .

\section{Materials and Methods}

Plant material. The genotype used for this study was Pistacia vera 'Mateur'. In vitro shoot-tip cultures of this clone were established from 3-year-old grafted trees with P. palestina seedlings as the rootstock. Vernalized $(2000 \mathrm{~h}$ below $7 \mathrm{C})$ trees were maintained in a screenhouse between April and June to cut down the risk of in vitro contamination. Every other week, before budbreak and during new shoot growth, trees were sprayed with a fungicide (fixed copper, 8-oxiquinolein sulfate, captan, or benomyl). On alternate weeks, $0.44 \mathrm{~mm} \mathrm{BA}$ and $0.14 \mathrm{~mm} \mathrm{GA}$, were applied to induce vigorous growth. All treatments included $0.1 \%(\mathrm{v} / \mathrm{v})$ Tween-20.

Medium and culture conditions. The medium (MSPV) contained the mineral nutrients devised by Murashige and Skoog ( 1962), except for lower concentrations of $\mathrm{NH}_{4} \mathrm{NO}_{3}$ and $\mathrm{CaCl}_{2} \mathrm{Z}_{2} \mathrm{H}_{2} \mathrm{O}$ (10.3 mM and $1.0 \mathrm{~mm}$, respectively), higher concentrations of $\mathrm{FeSO}_{4} \cdot 7 \mathrm{H}_{2} \mathrm{O}$ and $\mathrm{Na}_{2}$ EDTA $\bullet 2 \mathrm{H}_{2} \mathrm{O}$ (both $0.15 \mathrm{~mm}$ ), and $3 \%(\mathrm{w} / \mathrm{v})$ sucrose, myo-inositol (100 mg.liter $\left.{ }^{-1}\right)$, thiamine- $\mathrm{HCl}\left(1 \mathrm{mg} \cdot\right.$ liter $\left.^{-1}\right)$, 
nicotinic acid $\left(1 \mathrm{mg} \cdot\right.$ liter $\left.^{-1}\right)$, pyridoxine- $\mathrm{HCl}\left(1 \mathrm{mg} \cdot\right.$ liter $\left.^{-1}\right)$, glycine (2 mg.liter $\left.{ }^{-1}\right)$, L-glutamine (2 mg.liter $\left.{ }^{-1}\right)$, L-cysteine ( $\left.2 \mathrm{mg} \cdot \mathrm{liter}^{-1}\right)$, and $0.6 \%(\mathrm{w} / \mathrm{v})$ Difco Bacto agar. The $\mathrm{pH}$ was adjusted to 5.7 before autoclaving. BA and IBA were added to the multiplication medium before autoclaving. Other growth regulators used in shoot multiplication [gibberellic acid (GA,)] or root induction (IBA, IAA, and NAA) media were dissolved in dimethylsulfoxide (DMSO) (Schmitz and Skoog, 1970), which acts as a sterilant, and was added to the medium after autoclaving (50 $\mu \mathrm{l} \mathrm{DMSO} / 100 \mathrm{ml}$ medium). All chemicals were supplied by Sigma Chemical Co. (Alcobendas, Madrid), and Difco Bacto-Agar was supplied by Difco Laboratories (Detroit). During establishment and shoot multiplication, all cultures were kept at $25 \mathrm{C}$ under a photoperiod of $16 \mathrm{~h}$ of cool-white fluorescent light $\left(70 \mu \mathrm{mol} \cdot \mathrm{m}^{-2} \cdot \mathrm{s}^{-1}\right)$.

Explant establishment and shoot multiplication. New shoots were divided into 1- to 2-cm-long nodal segments. The explants were washed for $1 \mathrm{~h}$ by stirring in distilled water and surfacesterilized in $70 \%$ ethanol for $1 \mathrm{~min}$, followed by $0.5 \%$ (w/v) $\mathrm{NaOCl}$ with $0.1 \%(\mathrm{v} / \mathrm{v})$ Tween-20 for $10 \mathrm{~min}$. Each explant was rinsed individually three times with sterile distilled water, trimmed, and cultured in a tube containing $15 \mathrm{ml}$ of MSPV medium with $5 \mu \mathrm{M}$ BA. During the first 8 weeks, shoot-tip explants were subcultured weekly. Shoots that appeared uncontaminated were screened further forbacterial contamination in 523 medium (Viss et al., 1991), which consists of $1 \%(\mathrm{w} / \mathrm{v})$ sucrose, $0.8 \%(\mathrm{w} / \mathrm{v})$ casein hydroly-

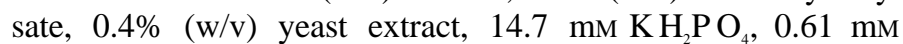
$\mathrm{MgSO}_{4} \cdot 7 \mathrm{H}_{2} \mathrm{O}$, and $0.8 \%$ (w/v) Difco Bacto agar. Streaked plates were incubated for 5 days, in the dark, and at 25C. Explants that showed bacterial growth on this medium were discarded. Branching and multiplication started about 12 weeks after initiation. For shoot multiplication, shoots or segments of at least $1 \mathrm{~cm}$ long were transferred every 3 weeks to flasks containing $100 \mathrm{ml}$ of MSPV medium supplemented with $5 \mu \mathrm{M}$ BA and $0.05 \mu \mathrm{M}$ IBA. Ten segments were transferred to each flask.

Shootmultiplication experiments. In the first experiment, MSPV medium was tested against standard MS medium (Murashige and Skoog, 1962), half-strength MS, woody plant medium (WPM) (Lloyd and McCown, 1980), and DKW-C medium used for walnut (McGranahan et al., 1987).

In the second experiment, a double-phase system was tested, consisting of $30 \mathrm{ml}$ of liquid MSPV medium without BA or IBA on top of the $100 \mathrm{ml}$ gelled phase. The liquid medium was added 3 weeks after cultures were initiated and cultures were maintained for an additional 2 weeks. Effects of silver thiosulfate (STS) at 0, $2.5,5,10$, or $20 \mu \mathrm{g} \cdot \mathrm{ml}^{-1}$ (Per1 et al., 1988) in the liquid phase were also determined. Silver thiosulfate was prepared by mixing 1 $\mathrm{AgNO}_{3}: 2 \mathrm{Na}_{2} \mathrm{~S}_{2} \mathrm{O}_{3} \cdot 5 \mathrm{H}_{2} \mathrm{O}(\mathrm{w} / \mathrm{w})$, filter-sterilized, and added to the medium after autoclavmg.

In the third experiment, effects of MeJA (Firmenich SA, Geneve, Switzerland) were tested. MeJA was dissolved in DMSO and added to MSPV medium after autoclaving. Medium was cooled before adding MeJA and rapidly solidified in an ice bath to reduce compound volatilization. MeJA at $0,0.3,1,3.2$, or $10 \mu \mathrm{M}$ was added to MSPV during three consecutive subcultures.

Each experiment, with a completely randomized design, consisted of three randomly selected replicate flasks with 10 shoots each per treatment level. These explants were from shoot-tip multiplication cultures. The experiments were repeated four times. The multiplication rate was recorded as number of shoots longer than $1 \mathrm{~cm}$ per cultured shoot after 3 weeks of culture.

Rooting experiments. For root induction and elongation, welldeveloped shoots (1 to $3 \mathrm{~cm}$ long) were transferred to MSPV medium with one-half the concentration of macronutrients. The experiments were conducted with micropropagated shoots from the 10th through the 20th subculture.

In the first three-factor experiment, the effects of various IBA, NAA, and IAA concentrations $(0,1,3.2,10$, or $31.6 \mu \mathrm{M})$ at two temperature regimes ( 25 or $28 \mathrm{C}$ ) were examined. Shoots were grown on auxin-containing medium for 1 week and then on auxinfree medium for 2 weeks.

In the second two-factor experiment, the effects of MeJA $(0$, $0.3,1,3.2$, or $10 \mu \mathrm{M}$ ) on rooting of shoots were determined under two conditions: at $25 \mathrm{C}$ with $31.6 / \mu \mathrm{M} \mathrm{NAA}$ in the induction medium and at $28 \mathrm{C}$ with $31.6 \mu \mathrm{M}$ IAA in the induction medium. The choice of auxins and temperature was based on the results of the first experiment.

Each experiment, with a completely randomized design, consisted of three randomly selected replicate flasks with 10 shoots each per treatment level. These explants were from shoot-tip multiplication cultures. The experiments were repeated four times. The percentage of rooted shoots per flask, number of roots per rooted shoot, and root length were determined.

Statistical tests included analysis of variance, separation of means by Fisher's protected LSD, and planned contrasts (Petersen, 1985). Auxin or MeJA concentrations were equally spaced on a logarithmic scale. Regression trends were obtained using orthogonal polynomial contrasts. The polynomial coefficients to partition the treatment sum of squares (SST) into components associated with successive terms of a polynomial equation and the regression equation were calculated according to Carmer and Seif (1963).

Acclimation. Rooted plantlets were washed and potted in trays with steam-sterilized $(100 \mathrm{C}, 1 \mathrm{~h}) 1$ peat : 1 perlite : 1 sand : 1 water (by volume). Plantlets were acclimated for 3 weeks in plastic boxes placed in a growth chamber at $24 \mathrm{C}$ under a 12-h photoperiod (300 $\mu \mathrm{mol} \cdot \mathrm{m}^{-2} \cdot \mathrm{s}^{-1}$ ) Boxes were gradually opened during the last week to lower the humidity. Acclimated plants were moved to a greenhouse in 16-cm-wide polypropylene containers with 2 peat : 1 sand (v/v) and covered with a plastic cup during the first 3 weeks.

\section{Results and Discussion}

Explant establishment and shoot multiplication. Three-yearold grafted mother trees maintained in a screen house were a good source of explants for the establishment of P. vera 'Mateur' shoottip cultures. Medium browning due to secretion of phenolic compounds occurred within a few hours after culture, but was diminished by frequent transfers to fresh medium during the first weeks after initiation. Necrosis at the base and decreased shoot growth were observed when explants were transferred infrequently. After screening for bacterial contamination in 523 medium (Viss et al., 1991) 10\% of explants was free of contamination.

Shoots of $P$. vera showed less leaf chlorosis and shoot-tip necrosis on MSPV than MS, DKW-C, or WPM media (data not shown). MSPV differs from MS medium in having one-half the concentration of $\mathrm{NH}_{4} \mathrm{~N} \mathrm{O}_{3}$, one-third the concentration of $\mathrm{CaCl}_{2} \cdot 2 \mathrm{H}_{2} \mathrm{O}$, and a higher Fe-EDTA concentration. In a detailed study with the same type of plant material, Abousalim and Mantel1 (1994) concluded that periodic immersion of cultures in liquid MS supplemented with $\mathrm{Ca}$ gluconate reduced the incidence of shoottip necrosis. In our work, shoot-tip necrosis was prevented by a shorter subculture period (every 3 weeks instead of 4 to 6 weeks), not by increasing the $\mathrm{CaCl}_{2} \cdot 2 \mathrm{H}_{2} \mathrm{O}$ concentration. We observed that increasing the $\mathrm{CaCl}_{2} \check{\mathrm{Z}}_{2} \mathrm{H}_{2} \mathrm{O}$ concentration to $6 \mathrm{mM}$ was detrimental to shoot growth and promoted leaf chlorosis,

Shoot-tips cultured on MSPV had multiplication rates slightly 
higher than 2 shoots per explant. Experiments were conducted to improve the multiplication rate. Delaying the subculture to 4 weeks did not encourage multiplication but increased the secretion of phenolic compounds and formation of a black callus at the shoot base. Multiplication was not improved by increasing the BA concentration to $20 \mu \mathrm{M}$, as suggested by Barghchi and Alderson (1989). Instead, severe hyperhydricity was observed. In contrast to the findings of Gonzalez and Frutos (1990), adding 0.3, 1, or $3 \mu \mathrm{M}$ GA, inhibited shoot elongation and induced leaf chlorosis.

Culturing shoot-tips in a double-phase system, with $30 \mathrm{ml}$ of liquid MSPV medium added after the first 3 weeks of culture, did not enhance shoot elongation but induced hyperhydricity along with the secretion of phenolic compounds. Hyperhydricity and medium browning were drastically reduced when the liquid phase of the double-phase system contained 5, 10, or $20 \mu \mathrm{g} \cdot \mathrm{ml}^{-1}$ STS. However, shoot elongation was not significantly enhanced. Moreover, adding STS during consecutive subcultures suppressed shoot growth and multiplication (data not shown). STS has improved shoot growth and leaf development of potato (Solanum tuberosum 'Bintje') shoot-tip cultures by adding 2 to $8 \mu \mathrm{g} \cdot \mathrm{ml}^{-1} \mathrm{STS}$ to the culture medium (Per1 et al., 1988).

In a preliminary experiment, MeJA at $0.01,0.1$, or $1 \mu \mathrm{M}$ had positive effects on shoot multiplication and leaf growth when present at $1 \mu \mathrm{M}$; therefore, a larger experiment was conducted to test the effects of MeJA. Adding 0.3, 1, or $3.2 \mu \mathrm{M}$ MeJA to MSPV significantly $(\mathrm{P}<0.001)$ improved shoot multiplication (Fig. 1) and favored leaf development compared to MSPV lacking MeJA. The optimal MeJA concentration was $1 \mu \mathrm{M}$. Leaf senescence and decreased shoot multiplication were observed at $10 \mu \mathrm{M} \mathrm{MeJA.} \mathrm{No}$ significant differences among subcultures were observed when MeJA was added to the MSPV during three consecutive subcultures (data not shown). These results agree with JA-stimulated shoot elongation and increased number of nodes per plant reported in grapevine stem cuttings (Ravnikar et al., 1990) and potato stem nodes (Ravnikar et al., 1992) when JA was present at 0.01 to $1 \mu \mathrm{M}$.

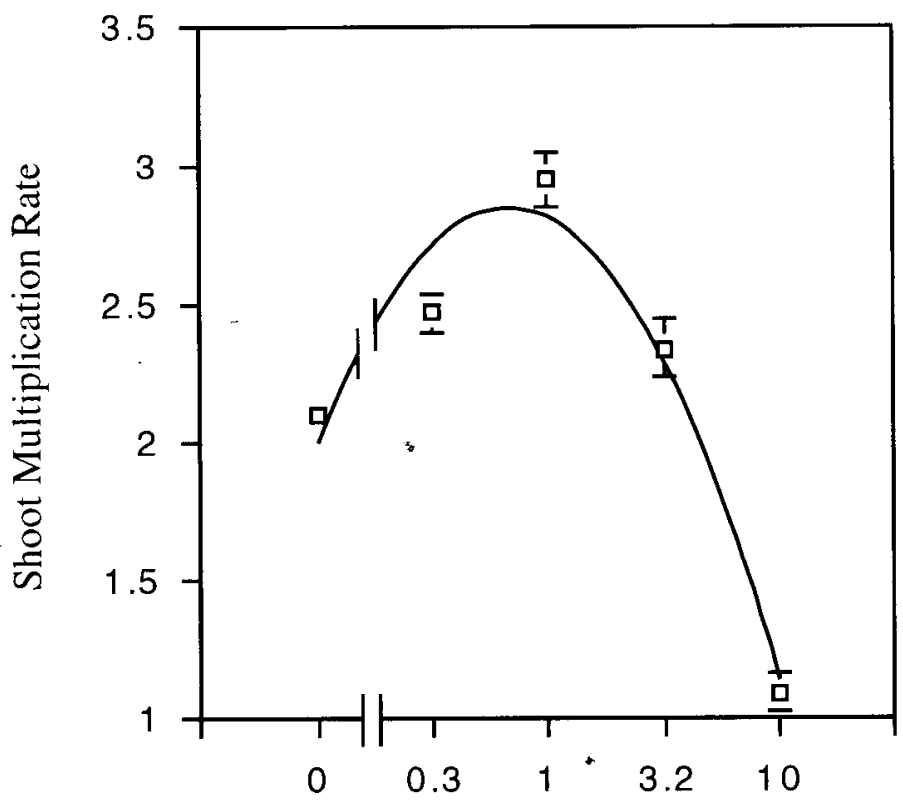

Methyl Jasmonate $(\mu \mathrm{M})$

Fig. 1. Effects of the concentration (log scale) of MeJA on shoot multiplication rates of Pistacia vera 'Mateur'. Vertical bars $=$ SE. The polynomial regression trend was quadratic.
Similar to our results with pistachio, higher concentrations (10 to $100 \mu \mathrm{M})$ of JA also inhibited lettuce seed germination and seedling growth (Yamane et al., 1981) and shoot elongation in grapevine and potato (Ravnikar et al., 1990, 1992).

Rooting. White callus was visible at the shoot base after 1 week of culture on auxin-containing MSPV medium. A subsequent passage on auxin-free MSPV for 2 weeks was sufficient to encourage root elongation. A significant interaction $(\mathrm{P}<0.001)$ for percentage of shoots forming roots was found between auxin type and auxin concentration when shoots were incubated at $25 \mathrm{C}$ (Fig. 2A). Contrary to previous reports (Barghchi and Alderson, 1989; Martinelli, 1988; Mederos and Carreño, 1991; Parfitt and Almehdi, 1994), IBA was not the best auxin to induce rooting of $P$. vera shoot cultures. In our study, NAA more effectively induced roots than IBA or IAA. No significant differences were found between IBA or IAA, regardless of their concentration. A maximum of $62 \%$ shoots forming roots was obtained with $31.6 \mu \mathrm{M}$ NAA, whereas only $15 \%$ of the shoots incubated in MSPV with $31.6 \mu \mathrm{M} \mathrm{IBA}$ or IAA formed roots. Our percentage of shoots forming roots was higher than the $40 \%$ obtained by Martinelli (1988) working with $P$.

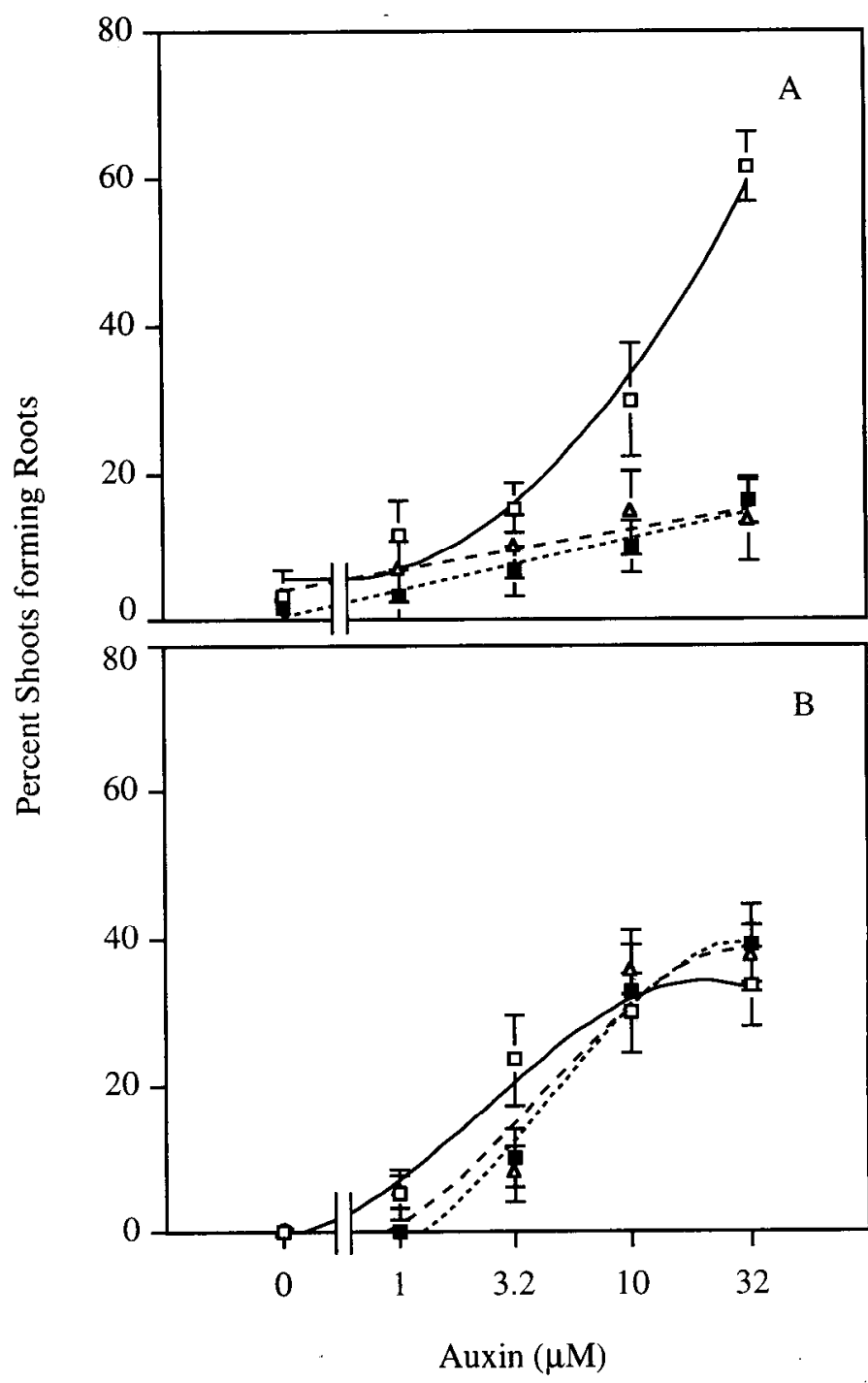

Fig. 2. Effects of the concentration (log scale) of NAA ( $\square)$, IBA ( $\square)$, and IAA ( $\Delta$ ) on the percentage of Pistacia vera 'Mateur' shoots forming roots at (A) 25C or (B) $28 \mathrm{C}$. Vertical bars $=\mathrm{SE}$. At $25 \mathrm{C}$, the polynomial regression trend was quadratic for NAA and linear for IBA and IAA. At 28C, the regression trend was cubic for NAA, IBA, and IAA. 

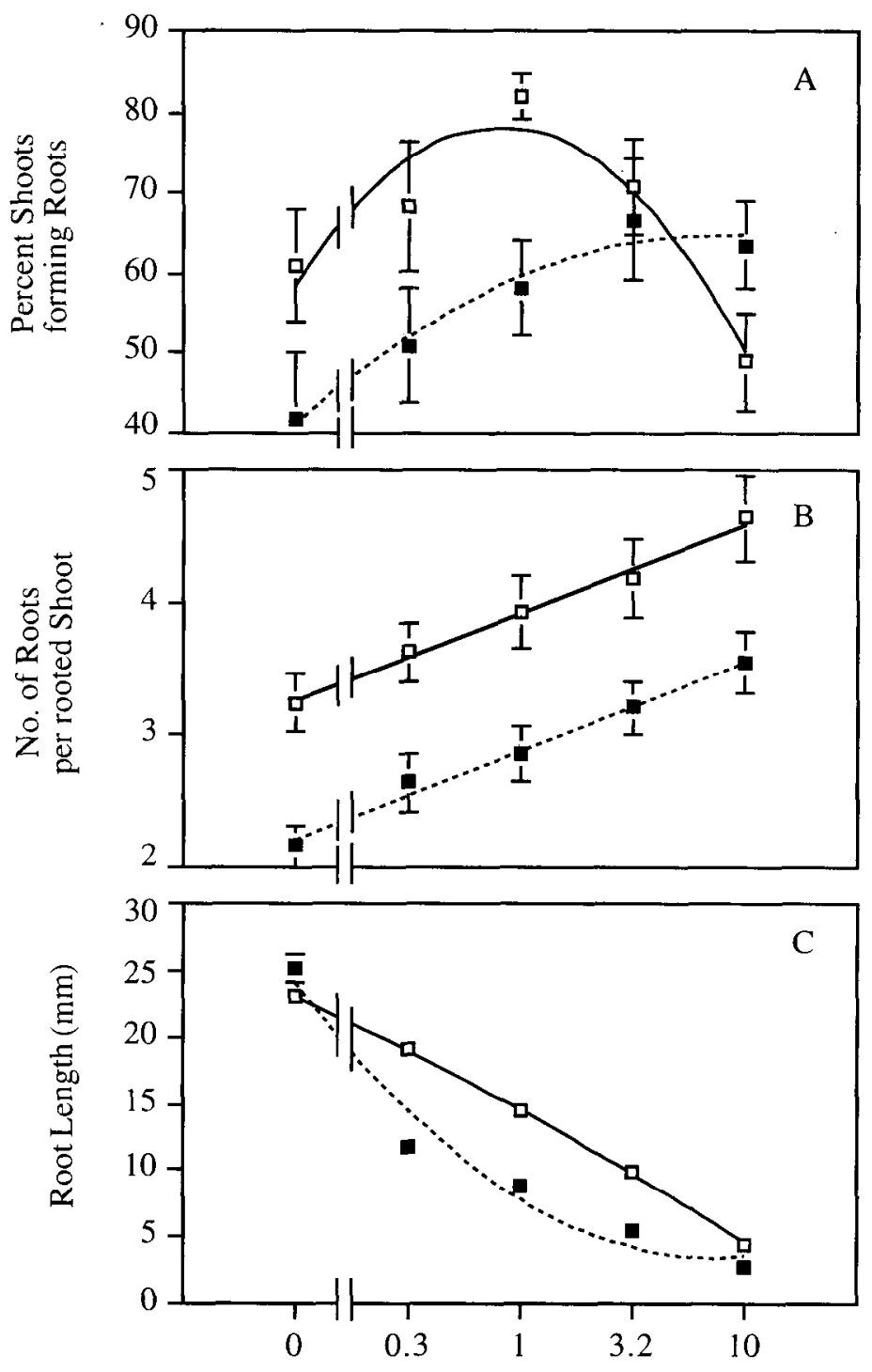

Methyl Jasmonate $(\mu \mathrm{M})$

Fig. 3. Effects of the concentration (log scale) of MeJA on (A) the percentage of shoots forming roots, (B) number of roots, and (C) root length of Pistacia vera shoots rooted at $25 \mathrm{C}(\square)$ or $28 \mathrm{C}(\boldsymbol{\square})$. Vertical bars $=\mathrm{sE}$. For the percentage of shoots forming roots, polynomial regression trends were quadratic. For number of roots, polynomial regression trends were linear. For root length, the regression trend was linear at $25 \mathrm{C}$ and quadratic at $28 \mathrm{C}$.

vera 'Kerman' or 'Peter'. Higher percentages $(88 \%)$ of shoots forming roots have been reported (Parfitt and Almehdi, 1994) using juvenile material ( $P$. vera 'Kerman' seedlings). In our work and that by Martinelli (1988) 3- to 4-year-old grafted trees were used as source of explants. Other studies have shown that juvenile $P$. vera plants root more readily than adult wood (Barghchi and Alderson, 1989; Gonzalez and Frutos, 1990).

When rooting was induced at $28 \mathrm{C}$, the auxin concentration significantly $(P<0.001)$ affected the percentage of shoots forming roots, regardless of the auxin type (Fig. 2B). The maximum percentage of shoots forming roots (37\%) was obtained with 31.6 $\mu \mathrm{M}$ auxin. However, at this temperature, IAA was preferred in subsequent experiments over NAA and IBA because the latter two induced shoot-tip senescence, callus production at the shoot base, and shorter, thicker roots. Consequently, two root-inducing treat- ments were chosen for further rooting experiments: 1) $31.6 \mu \mathrm{M}$ NAA for shoots maintained at $25 \mathrm{C}$ and 2) $31.6 \mu \mathrm{M}$ IAA for shoots maintained at $28 \mathrm{C}$. As indicated by these results, temperature control is important during the rooting phase.

During the 2 weeks of culture in auxin-free medium, root elongation was rapid but not uniform, resulting in a few extremely long roots per shoot. In addition, roots from $P$. vera 'Mateur' were fragile and easily broken during transfer of plantlets to soil, making their acclimation more difficult. Adding MeJA to auxin-containing media and auxin-free medium increased the percentage of shoots forming roots and number of roots per rooted shoot, but inhibited root length (Fig. 3). The concentration of MeJA $(P=$ $0.050)$ and auxin-temperature regime $(P=0.033)$ significantly affected the percentage of shoots forming roots (Fig. 3A). However, no significant interaction was observed between auxintemperature regime and MeJA concentration for the percentage of shoots forming roots. Maximum induction of root formation was obtained with the addition of 1 or $3.2 \mu \mathrm{M}$ MeJA to the rooting medium containing NAA (25C incubation) and IAA (28C incubation), respectively. Volatility of MeJA may explain the higher concentration needed to obtain maximum root formation when cultures were maintained at 28 rather than $25 \mathrm{C}$.

Regardless of MeJA concentrations, more roots per rooted shoot were obtained $(P<0.001)$ with NAA $(25 \mathrm{C}$ incubation) than with IAA (28C incubation). Adding $1,3.2$, or $10 \mu \mathrm{m}$ MeJA improved $(P=0.050)$ the average root number, regardless of the auxin-temperature regime (Fig. 3B). Adding 0.3 to $10 \mu \mathrm{M}$ MeJA significantly $(\mathrm{P}<0.001)$ reduced root length (Figs. $3 \mathrm{C}$ and 4$)$. Root length was more uniform when MeJA was added to the root induction and elongation media, as indicated by the small variation in each treatment (Fig. 3C).

Similar effects of JA on root number and length have been reported with other plant species. Concentrations of JA higher than $0.1 \mu \mathrm{M}$ inhibited root elongation in $P$. vera shoot-tips in our study and also inhibited root elongation of grapevine (Ravnikar et al., 1990), potato (Ravnikar et al., 1992), and lettuce (Yamane et al., 1981). However, Benedicic et al. (1991) observed that 1 to $10 \mu \mathrm{M}$ JA stimulated root elongation in bean (Phaseolus vulgaris L.). Further, none of the MeJA concentrations tested in our study induced the lateral root formation in $P$. Vera, which conflicts with results obtained using potato stem nodes (Ravnikar et al., 1992). Thus, as indicated by Sembdner and Parthier (1993), the plant material and developmental stage are important factors in discriminating between physiological and supraoptimal concentrations.

The best protocol for shoot-tip micropropagation of Pistacia vera 'Mateur' can be summarized as follows. Explants were best established when obtained from young grafted trees, sterilized, and weekly transferred to fresh MSPV medium with $5 \mu \mathrm{M}$ BA. Before the multiplication stage starts, screening for bacterial contamination is advisable. Highest multiplication rates were obtained by transfers every 3 weeks to MSPV medium supplemented with $5 \mu \mathrm{M} \mathrm{BA}, 0.05 \mu \mathrm{m} \mathrm{IBA}$, and $1 \mu \mathrm{m} \mathrm{MeJA}$. Root formation was greatest when shoots, incubated at $25 \mathrm{C}$, were cultured for 1 week on MSPV medium (one-half the concentration of macronutrients) containing $31.6 \mu \mathrm{M}$ NAA and $1 \mu \mathrm{M}$ MeJA, followed by 2 weeks of culture on the same medium but lacking NAA.

Acclimation. Initial acclimation experiments of $P$. vera 'Mateur' plantlets were unsuccessful following the protocol for acclimation described in Materials and Methods. Only 24 (10\%) of 240 plants survived when transferred to soil. Reduced. root length and uniform root elongation were desirable to avoid root breakage of the 


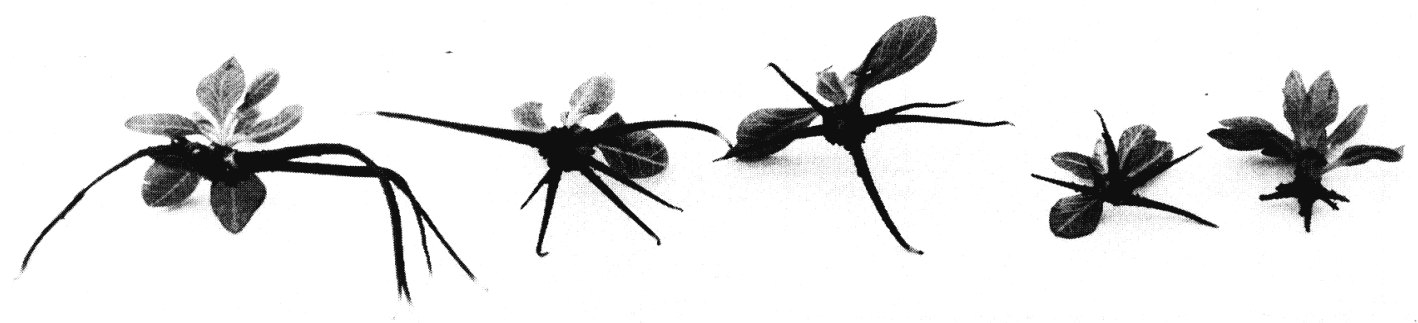

$\begin{array}{lllll}0 & 0.3 & 1 & 3.2 & 10\end{array}$

\section{$\boldsymbol{\mu M} \mathbf{M e J A}$}

Fig. 4. Pistacia Vera 'Mateur' plantlets rooted in the presence of $0,0.3,1,3.2$, or $10 \mu \mathrm{M}$ MeJA.

fragile $P$. vera roots during transfer to soil. Plantlets obtained by rooting shoots in medium containing 1 or $3.2 \mu \mathrm{M} \mathrm{MeJA} \mathrm{had} \mathrm{more}$ abundant and shorter roots and, consequently, could be transferred more easily to soil, resulting in much higher survival percentage [80 $(73 \%)$ of 110 plants]. However, independent of MeJA or auxin-temperature regime, only $30 \%$ of the acclimated plants resumed growing the following season. This decrease in survival may be due to the absence of vesicular-arbuscular mycorrhizae, which may be important in helping growth of in vitro propagated $P$. vera plantlets (Estaun et al., 1990; Schubert and Martinelli, 1988). Self-rooted 'Mateur' trees obtained by micropropagation have been placed in the field for further studies on their agronomic performance.

\section{Literature Cited}

Abousalim, A. and S.H. Mantell. 1992. Micrografting of pistachio (Pistacia vera L. cv. Mateur). Plant Cell Tissue Organ Cult. 29:231-234.

Abousalim, A. and S.H. Mantell. 1994. A practical method for alleviating shoot-tip necrosis symptoms in in vitro shoot cultures of Pistucia vera cv. Mateur. J. Hort. Sci. 69(2):357-365.

Barghchi, M. and P.G. Alderson. 1983. In vitro propagation of Pistuciu veru L. from seedling tissues. J. Hort. Sci. 58(3):435-445.

Barghchi, M. and P.G. Alderson. 1989. Pistachio (Pistucia vera L.), p. 6898. In: Y.P.S. Bajaj (ed.). Biotechnology in agriculture and forestry. vol. 5. Trees II. Springer-Verlag, Berlin Heidelberg.

Benedicic, D., M. Ravnikar, and N. Gogala. 1991. The influence of jasmonic acid on the development of Phaseolus vulgaris shoot culture. Acta Hort. 289:85-86.

Canner, S.G. and R.D. Seif. 1963. Calculation of orthogonal coefficients when treatments are unequally replicated and/or unequally spaced. Agron. J. 55:387-389

Estaun, V., C. Calvet, and A. Camprubi. 1990. Vesicular-arbuscular mycorrhizae on Pistuciu sp. Symbiosis 9:309-313

Gonzalez, A. and D. Frutos. 1990. In vitro culture of Pistucia vera L. embryos and aged trees explants, p. 335-398. In: R. Rodriguez, R. Sanchez Tames, and D.J. Durzan (eds.). Plant aging: Basic and applied approaches. Plenum Press, New York.

Lloyd, G. and B. McCown. 1980. Commercially feasible micropropagation of mountain laurel, Kalmia latifolia, by use of shoot-tip culture. Proc. Intl. Plant Prop. Soc. 30:421-427.

McGranahan, G.H., J.A. Driver, and W. Tulecke. 1987. Tissue culture of Juglans, p. 261-271. In: J.M. Bonga and D.J. Durzan (eds.). Cell and tissue culture in forestry. vol. 3. Case histories: Gymnosperms, angiosperms and palms. Martinus Nijhoff Publishers, Dordrecht.

Martinelli, A. 1988. Use of in vitro techniques for selection and cloning of different Pistacia species. Acta Hort. 227:436-437.

Mederos, S. and I. Carreño. 1991. In vitro organogenesis of Pistacia vera L. cv Mateur. In Vitro Cell. Dev. Biol. 27(3):108. (Abstr.)

Meyer, A., 0. Miersch, C. Büttner, W. Dathe, and G. Sembdner. 1984. Occurrence of the plant growth regulator jasmonic acid in plants. J. Plant Growth Regulat. 3:1-8.

Murashige, T. and F. Skoog. 1962. A revised medium for rapid growth and bioassays with tobacco tissuecultures. Physiol. Plant. 15:473-497.

Parfitt, D.E. and A.A. Almehdi. 1994. Use of a high CO2 atmosphere and medium modifications for the successful micropropagation of pistachio. Scientia Hort. 56:321-329.

Parthier, B. 1990. Jasmonates: hormonal regulators or stress factors in leaf senescence? J. Plant Growth Regulat. 9:57-63.

Perl, A., D. Aviv, and E. Galun. 1988. Ethylene and in vitro culture of potato: Suppression of ethylene generation vastly improves protoplast yield, plating efficiency and transient expression of an alien gene. Plant Cell Rpt. 7:403-406.

Petersen, R.G. 1985. Design and analysis of experiments. 1st ed. Marcel Dekker, New York.

Ravnikar, M., J. Rode, N. Gogala, and D. Benedicic. 1990. Regulation of organogenesis with jasmonic acid. Acta Hort. 280:169-172.

Ravnikar, M., B. Vilhar, and N. Gogala. 1992. Stimulatory effects of jasmonic acid on potato stem node and protoplast culture. J. Plant Growth Regulat. 11:29-33.

Schmitz, R.Y. and F. Skoog. 1970. The use of dimethylsulfoxide as a solvent in the tobacco bioassay for cytokinins. Plant Physiol. 45:537-538.

Schubert, A. and A. Martinelli. 1988. Effect of vesicular-arbuscular mycorrhizae on growth of in vitro propagated Pistacia integerrima. Acta Hort. 227:441-443.

Sembdner, G. and B. Parthier. 1993. The biochemistry and the physiological and molecular actions of jasmonates. Annu. Rev. Plant Physiol. Plant Mol. Biol. 44:569-589.

Staswick, P.E. 1992. Jasmonate, genes, and fragrant signals. Plant Physiol. 99:804-807.

Viss, P.R., E.M. Brooks, and J.A. Driver. 1991. A simplified method for the control of bacterial contamination in woody plant tissue culture. In Vitro Cell. Dev. Biol. 27:42.

Yamane, H., H. Takagi, H. Abe, T. Yokota, and N. Takahashi. 1981. Identification of jasmonic acid in three species of higher plants and its biological activities. Plant Cell Physidl. 22(4):689-697. 